\title{
The enhanced tumor inhibitory effects of gefitinib and L-ascorbic acid combination therapy in non-small cell lung cancer cells
}

\author{
KYOUNG EUN LEE ${ }^{1 *}$, EUNSIL HAHM $^{2 *}$, SEYEON BAE $^{2}$, JAE SEUNG KANG $^{2}$ and WANG JAE LEE ${ }^{2}$ \\ ${ }^{1}$ Division of Hematology-Oncology, Department of Internal Medicine, School of Medicine, \\ Ewha Womans University, Seoul 07985; ${ }^{2}$ Department of Anatomy and Tumor Immunity Medical Research Center, \\ College of Medicine, Seoul National University, Seoul 03080, Republic of Korea
}

Received May 10,2016; Accepted March 3, 2017

DOI: 10.3892/ol.2017.6109

\begin{abstract}
Despite documentation of successful therapy with epidermal growth factor receptor (EGFR) tyrosine kinase inhibitors in patients with lung cancer, the response rate of patients treated with this therapy remains low. The present study investigated whether L-ascorbic acid serves an adjuvant role in vitro when combined with the EGFR tyrosine kinase inhibitor gefitinib (Iressa ${ }^{\circledR}$ ) in lung cancer cell lines. A total of three human lung cancer cell lines were used. The antiproliferative effects and changes in the cell cycle and expression of intracellular signaling molecules, including extracellular signal-regulated kinases (Erk), signal transducer and activator of transcription 3 (Stat3) and protein kinase B (Akt), were measured in cells treated with gefitinib and/or L-ascorbic acid at various concentrations. When combined with gefitinib, L-ascorbic acid exhibited an additive effect on cell proliferation in all gefitinib-sensitive and gefitinib-resistant cell lines. A decrement of $\sim 40 \%$ was observed with a low dose $0.5 \mathrm{mM}$ L-ascorbic acid and gefitinib in the relatively gefitinib-resistant A549 cell line $(85.6 \pm 5.4 \%$ with gefitinib alone vs. $52.7 \pm 7.3 \%$ with combination therapy; $\mathrm{P}=0.046$ ). The downregulation of intracellular signaling cascades, including EGFR, Akt, Erk and Stat3, was also observed. L-Ascorbic acid serves an adjuvant role when administered in combination with gefitinib; however, the degree of inhibition of cell proliferation differs between lung cancer cell lines.
\end{abstract}

Correspondence to: Dr Wang Jae Lee, Department of Anatomy and Tumor Immunity Medical Research Center, College of Medicine, Seoul National University, 103 Daehang-ro, Chongno-gu, Seoul 03080, Republic of Korea

E-mail: kinglee@snu.ac.kr

*Contributed equally

Key words: L-ascorbic acid, gefitinib, vitamin C, non-small cell lung carcinoma, epidermal growth factor receptor

\section{Introduction}

Lung cancer is the leading cause of cancer-associated mortality worldwide $(1,2)$. A total of one-third of patients with lung cancer initially present at an advanced stage, when only palliative therapies are typically available $(1,2)$. Although complete resection of the lung is the only known curative therapy in stages I-III of this disease, a number of patients do experience relapse following surgery (3). A total of one-third of patients with lung cancer survive for a number of years following diagnosis (3). Recently, there has been a paradigm shift in lung cancer therapeutics, from the use of conventional cytotoxic drugs to the use of variable molecular-targeted therapeutics, including gefitinib, erlotinib and crizotinib (4).

The epidermal growth factor receptor (EGFR) is a member of the transmembrane tyrosine kinase receptor family and its expression is elevated in a number of solid tumors. Initially, the overexpression of EGFR was demonstrated to be a strong prognostic indicator in head and neck, ovarian, cervical, bladder and esophageal cancer (5). Numerous trials aimed at identifying the benefits of administering anti-EGFR therapies to patients with cancer have been conducted $(6,7)$. There are currently two types of therapeutics available for inhibiting EGFR: One is a monoclonal antibody against EGFR and the other includes small-molecule inhibitors of EGFR tyrosine kinase (4). Gefitinib, trade name Iressa ${ }^{\circledR}$, is a small molecule that inhibits EGFR tyrosine kinase activity, and is the first molecular-targeted agent registered to treat advanced non-small cell lung cancer (NSCLC). Gefitinib trials have demonstrated that there is an overall response rate of $10-20 \%$ in patients with advanced NSCLC, which could be as high as $70 \%$ in patients with EGFR gene mutations when used as a first-line treatment $(8,9)$. There are two biomarkers, the presence of the EGFR gene mutations and an increase in gene copy number, known to be potent predictors of the response to gefitinib $(10,11)$. The presence of mutations in the EGFR gene is a major determinant of the gefitinib response; these mutations are small deletions affecting amino acids 747-750, or are point mutations (12-15).

There are four obstacles involved in the resistance to gefitinib that have recently been identified $(16,17)$. The first is the activation of alternative tyrosine kinase receptors that bypass the EGFR pathway. The second is the constitutive activation 
of signaling pathways downstream of the EGFR pathway, including the phosphoinositide 3-kinase/protein kinase B (Akt) pathway or proto-oncogene tyrosine-protein kinase Src family kinases, which induce resistance. The third is the ligand-independent activation of EGFR and the associated resistance to therapy. The fourth is a secondary EGFR mutation which changes the sensitivity to EGFR inhibitors. Efforts to overcome these complications involved in the resistance to gefitinib include the use of tyrosine kinase inhibitors that target other molecules; however, many limitations remain (18).

In the case of other molecular-targeted therapeutics, such as imatinib mesylate, changing the redox status with L-ascorbic acid restores drug sensitivity in imatinib-resistant cell lines. Previous studies have revealed that oxidative stress increases phosphorylation of the EGFR in keratinocytes (19-21). The antioxidant activity of L-ascorbic acid (vitamin C, water-soluble L-ascorbic acid) is achieved primarily via its ability to donate electrons and therefore function as a reducing agent (22). Cell signaling activities and the expression of associated molecules are sensitive to exogenous and intracellular redox status, and L-ascorbic acid serves a role in downregulating the expression of certain signaling molecules, including nuclear factor- $\kappa \mathrm{B}$, activator protein-1, Fos proto-oncogene and Jun proto-oncogene, and in regulating apoptosis (23).

There is considerable debate about whether L-ascorbic acid serves a therapeutic role in cancer. Recent reports have established that L-ascorbic acid also acts as a pro-oxidant and, depending on the dose, cell type and ability to stimulate apoptosis, may kill cancer cells (24). In human colon cancer cell lines, L-ascorbic acid functions as a potent antioxidant and blocks the chemotherapy-mediated induction of apoptosis (25). These results support the hypothesis that antioxidants may protect cancer cells from the free radical damage induced by chemotherapy. In addition to oxidation, L-ascorbic acid may serve a modulatory role in cellular phosphorylation-dephosphorylation events $(20,26-28)$. However, the mechanisms underlying these effects are currently unclear. Clinical trials of antioxidant plus chemotherapy regimens in patients with cancer are uncommon, due to concerns over inhibiting the effect of chemotherapy via decreasing the production of reactive oxygen species (ROS) (25). However, EGFR tyrosine kinase inhibitors exhibit a different mechanism of action when administered with cytotoxic chemotherapy to kill cancer cells (29).

In the present study, the EGFR tyrosine kinase inhibitor gefitinib was used as an apoptotic stimulus in lung cancer cell lines, and L-ascorbic acid was used as an adjuvant, in order to kill cancer cells. The aims of the present study were to evaluate whether L-ascorbic acid when co-administered with gefitinib therapy serves an additive or synergistic tumor-inhibitory role, and to elucidate the mechanisms underlying its effects in NSCLC cell lines.

\section{Materials and methods}

Cell lines. Three human NSCLC cell lines, A549, Calu-3 and HCC827, were obtained from the American Type Culture Collection (Manassas, VA, USA). HCC827 possesses an acquired mutation in the EGFR tyrosine kinase domain
(E746-A750 deletion), and the other two cell lines contain a wild-type EGFR tyrosine kinase domain. The cells were cultured in complete RPMI-1640 (Thermo Fisher Scientific, Inc., Waltham, MA USA) supplemented with $2 \mathrm{mM}$ L-glutamine, $100 \mathrm{U} / \mathrm{ml}$ penicillin, $100 \mu \mathrm{g} / \mathrm{ml}$ streptomycin and $10 \%$ heat-inactivated fetal bovine serum (Thermo Fisher Scientific, Inc.), and were used for experiments whilst in the log phase of growth.

Reagents. Gefitinib (ZD1839; trade name Iressa ${ }^{\mathrm{TM}}$ ) was kindly provided by AstraZeneca Pharmaceuticals (Macclesfield, UK) and was dissolved in dimethyl sulfoxide at a stock concentration $10 \mathrm{mM}$ and stored at $-20^{\circ} \mathrm{C}$ for in vitro experiments. L-ascorbic acid (sodium salt) was purchased from Sigma-Aldrich (St. Louis, MO, USA). For the flow cytometric analysis, a phycoerythrin-conjugated mouse anti-human EGFR antibody was purchased from BD Pharmingen (San Diego, CA, USA). For the western blot analysis, antibodies against EGFR (cat. no. 4267S; dilution, 1:1,000), phosphorylated (p)-EGFR [Tyr845 (cat. no. 6963S; dilution, 1:1,000), Tyr992 (cat. no. 2235S; dilution, 1:1,000) and Tyr1068 (cat. no. 2234S; dilution, 1:1,000)], Akt (cat. no. 9272S; dilution, 1:1,000), p-Akt (cat. no. 4060S; dilution, $1: 1,000)$, signal transducer and activator of transcription 3 (Stat3; cat. no. 9139S; dilution, 1:1,000) and p-Stat3 (cat. no. 9145S; dilution, 1:1,000) were purchased from Cell Signaling Technology, Inc. (Danvers, MA, USA). Antibodies against extracellular signal-related kinase (Erk; cat. no. sc-94; dilution, 1:1,000), p-Erk (cat. no. sc-7383; dilution, 1:1,000) and $\beta$-actin (cat. no. sc-47778; dilution, 1:2,000) were purchased from Santa Cruz Biotechnology, Inc. (Dallas, TX, USA). Trypan blue and 7-aminoactinomycin D were purchased from Sigma-Aldrich (Merck KGaA, Darmstadt, Germany).

Cell proliferation and viability assays. A total of $8 \times 10^{5}$ cells from each cell line were cultured in T25 culture flasks at $37^{\circ} \mathrm{C}$ in a $5 \% \mathrm{CO}_{2}$ humidified incubator, with or without dissolved L-ascorbic acid and/or gefitinib in PBS at 0, 20 and $40 \mathrm{mM}$ gefitinib in A549 cells, 0.0.5 and 1.0 mM in Calu-3 cells, 0, 2.5 and $5.0 \mu \mathrm{M}$ in HCC827 cells, and 0 and $0.5 \mathrm{mM} \mathrm{L-ascorbic}$ acid in A549 cells, 0, 2.5 and $5.0 \mathrm{mM}$ in Calu-3 cells, and 0, 0.5 and $1.0 \mathrm{mM}$ in HCC827 cells. The cells were pretreated with $\mathrm{L}$-ascorbic acid for $1 \mathrm{~h}$ and then treated with gefitinib for $48 \mathrm{~h}$ at room temperature. The number of cells and the viability of the cells were determined using a Trypan blue dye exclusion assay. An alternative method to monitor cell proliferation, the AlamarBlue $^{\circledR}$ assay (cat. no. BUF012A; Bio-Rad Antibodies, Oxford, UK), was also used. AlamarBlue ${ }^{\circledR}$ is a redox indicator that is reduced by reactions innate to cellular metabolism (30). Thus, it provides an indirect measure of the number of viable cells. The cells $\left(5 \times 10^{3}\right)$ were seeded onto a 96 -well plate and then treated with the aforementioned doses of L-ascorbic acid and/or gefitinib for $48 \mathrm{~h}$ at $37^{\circ} \mathrm{C}$. AlamarBlue ${ }^{\circledR}(10 \% \mathrm{v} / \mathrm{v}$ in medium) was subsequently added to the cells, the cells were incubated for $6 \mathrm{~h}$ at $37^{\circ} \mathrm{C}$ and fluorescence was measured at $530 \mathrm{~nm}$ excitation and $590 \mathrm{~nm}$ emission wavelengths in a spectrofluorometer (Fluoroskan Ascent ${ }^{\mathrm{TM}}$ FL; Labsystems Diagnostics Oy, Vantaa, Finland). The results are expressed as a percentage relative to the total cell number, and the groups 
that were not treated with L-ascorbic acid and gefitinib were used as control group.

Detection of intracellular ROS and cell cycle analysis. Cells from the three lung cancer cell lines were seeded into a 96-well plate at a density of $1 \times 10^{4}$ cells/well and incubated with $50 \mathrm{mM} \mathrm{2',7'-dichlorodihydrofluorescein} \mathrm{diacetate}$ (Sigma-Aldrich; Merck KGaA) for 5, 10, 15, 20, 25 and $30 \mathrm{~min}$ at $37^{\circ} \mathrm{C}$ in a $5 \% \mathrm{CO}_{2}$ humidified incubator. The cells were then analyzed using a CytoFluor 2350 plate reader (EMD Millipore, Billerica, MA, USA) with the excitation wavelength set at $485 \mathrm{~nm}$ and the emission wavelength at $530 \mathrm{~nm}$. For cell cycle analydsis, cells were pretreated with L-ascorbic acid in complete medium for $1 \mathrm{~h}$ and then treated with gefitinib for $48 \mathrm{~h}$ at $37^{\circ} \mathrm{C}$. The cells were then trypsinized, washed twice with cold PBS and centrifuged for $5 \mathrm{~min}$ with $200 \mathrm{x}$ g at room temperature. The pellet was resuspended in $1 \mathrm{ml}$ cold PBS and $4 \mathrm{ml}$ cold ethanol for $30 \mathrm{~min}$ at $4^{\circ} \mathrm{C}$. The cells were centrifuged at $200 \mathrm{x} \mathrm{g}$ for $5 \mathrm{~min}$, and the pellet was washed twice with cold PBS, suspended in $500 \mu 1$ propidium iodide staining solution (BD Pharmingen) and analyzed by flow cytometry BD FACSCalibur (BD Biosciences, Franklin Lakes, NJ, USA).

Western blotting. The cells were lysed and the proteins were extracted in a buffer containing $50 \mathrm{mM}$ Tris- $\mathrm{HCl}(\mathrm{pH} 7.4), 1 \%$ NP-40, $0.25 \%$ sodium deoxycholate, $150 \mathrm{mM} \mathrm{NaCl}, 1 \mathrm{mM}$ EDTA, $50 \mathrm{mM} \mathrm{NaF}, 1 \mathrm{mM}$ sodium orthovanadate, $1 \mathrm{mM}$ phenylmethylsulfonyl fluoride and a protease inhibitor cocktail (Sigma-Aldrich; Merck KGaA). The protein concentration was measured using a Bio-Rad Protein Assay kit (Bio-Rad Laboratories, Inc., Hercules, CA, USA). Equal amounts of protein (20-30 $\mu \mathrm{g}$ ) were resolved using $8 \%$ (for EGFR and p-EGFR) or 12\% [for Akt, p-Akt (Ser473), Erk, p-Erk, Stat3, p-Stat 3 and $\beta$-actin] SDS-PAGE and transferred onto nitrocellulose membranes. The membranes were blocked with $5 \%$ nonfat milk and $0.1 \%$ Tween-20-PBS for $1 \mathrm{~h}$ at RT with gentle agitation, washed with $0.1 \%$ Tween $20-\mathrm{PBS}$, and then exposed to the relevant primary antibody for $1 \mathrm{~h}$ at room temperature. The primary antibodies were diluted 1:1,000 in $0.1 \%$ Tween-20-PBS; the antibodies included anti-EGFR (cat. no. 4267S), anti-p-EGFR (Tyr845; cat. no. 6963S), anti-p-EGFR (Tyr992; cat. no. 2235S), anti-p-EGFR (Tyr1068; cat. no. 2234S), anti-Akt (cat. no. 9272S) and anti-p-Akt (Ser473; cat. no. 4060S) from Cell Signaling Technology, Inc.; anti-Erk (cat. no. sc-94) and anti-p-Erk (cat. no. sc-7383) from Santa Cruz Biotechnology, Inc. Subsequent to washing, the blots were exposed to a biotin-conjugated rabbit developed anti-mouse (cat. no. sc-358919; dilution, 1:1,000; Santa Cruz Biotechnology, or mouse developed anti-rabbit antibody (cat. no. sc-2491; dilution, 1:1,000; Santa Cruz Biotechnology,) for $1 \mathrm{~h}$ at room temperature. The membranes were then washed, incubated with a 1:5,000 dilution of streptavidin-horseradish peroxidase at room temperature, and the immunoreactive proteins were visualized using an ECL detection system (GE Healthcare Life Sciences, Chalfont, UK).

Statistical analysis. The results are presented as the mean, with error bars representing the standard deviation. Statistical analyses were performed using SPSS v.18 (SPSS, Inc., Chicago,
IL, USA). Non-parametric tests (Mann-Whitney U test) were used to evaluate significant differences among the continuous variables and the Kruskal-Wallis test was used to assess the statistical significance. For multiple comparisons, MedCalc ${ }^{\circledR}$ software for Windows (v.16.1) was used. (MedCalc ${ }^{\circledR}$ Software, Mariakerke, Belgium) $\mathrm{P}<0.05$ was considered to indicate a statistically significant difference.

\section{Results}

Increased expression of EGFR is induced by L-ascorbic acid or gefitinib in NSCNC cell lines. Cell surface EGFR protein expression was observed in NSCLC cell lines treated with or without L-ascorbic acid and/or gefitinib. When L-ascorbic acid and gefitinib were administered together, a $91.8 \%$ of cells expressed surface EGFR proteins, as compared with $35.3 \%$ of untreated Calu-3 cells. Treatment with gefitinib alone increased surface EGFR expression in Calu-3 cells, compared with treatment with L-ascorbic acid alone (88.9 vs. $64.5 \%$ of cells; $\mathrm{P}<0.05$ ). However, co-treatment with gefitinib and L-ascorbic acid resulted in no significant increase in EGFR expression, compared with treatment with gefitinib alone (91.8 vs. $88.9 \%$ of cells). In untreated A549 cells, $60.4 \%$ of cells expressed surface EGFR protein; this percentage was higher compared with that in untreated Calu-3 cells. The two agents demonstrated a tendency to increase EGFR expression in A549 cells; however, L-ascorbic acid exhibited no synergistic or additional effect on EGFR expression when co-administered with gefitinib. By contrast, L-ascorbic acid and gefitinib administered in combination decreased EGFR expression levels in A549 cells: 63.3\% of cells co-treated with the two agents expressed the EGFR protein, compared with $80.5 \%$ of cells treated with L-ascorbic acid alone and $72.4 \%$ treated with gefitinib alone, although no significance was observed.

Effects of gefitinib and L-ascorbic acid on cancer cell growth and proliferation. A549 is a lung cancer cell line that is resistant to EGFR tyrosine kinase inhibitors. Proliferation of these cells was inhibited with high doses of gefitinib; however, relatively low doses of L-ascorbic acid $(0.5 \mathrm{mM})$ administered with gefitinib inhibited cell proliferation to a greater extent $(\mathrm{P}=0.046$; Fig. 1A). The addition of $0.5 \mathrm{mM}$ L-ascorbic acid to $20 \mu \mathrm{M}$ gefitinib inhibited cellular proliferation by $>32 \%(85.6 \pm 5.4$ vs. $52.7 \pm 7.3 \%$ of the total number of cells; $\mathrm{P}=0.046)$. The inhibitory effect of gefitinib on Calu-3 cells, which exhibit the wild-type EGFR but are sensitive to gefitinib, was $\sim 60 \%$ of that observed in the control Calu-3 cells. The additional L-ascorbic acid significantly inhibited the proliferation of Calu-3 tumor cells at each concentration level of gefitinib (overall, $\mathrm{P}=0.027$, no gefitinib; $\mathrm{P}=0.039$, $0.5 \mu \mathrm{M}$ gefitinib; and $\mathrm{P}=0.127,1 \mu \mathrm{M}$ gefitinib, respectively; Fig. 1B). The additional significant inhibitory effect of the L-ascorbic acid was also observed in gefitinib-sensitive HCC827 cells at each gefitinib concentration (overall, $\mathrm{P}=0.066, \mathrm{P}=0.039$ and $\mathrm{P}=0.027$, respectively; Fig. $1 \mathrm{C})$. The AlamarBlue assay used to measure growth inhibition and the Trypan blue dye exclusion assay demonstrated a similar pattern of inhibition (data not presented). Microscopic examination of Calu-3 cells revealed that they experienced 

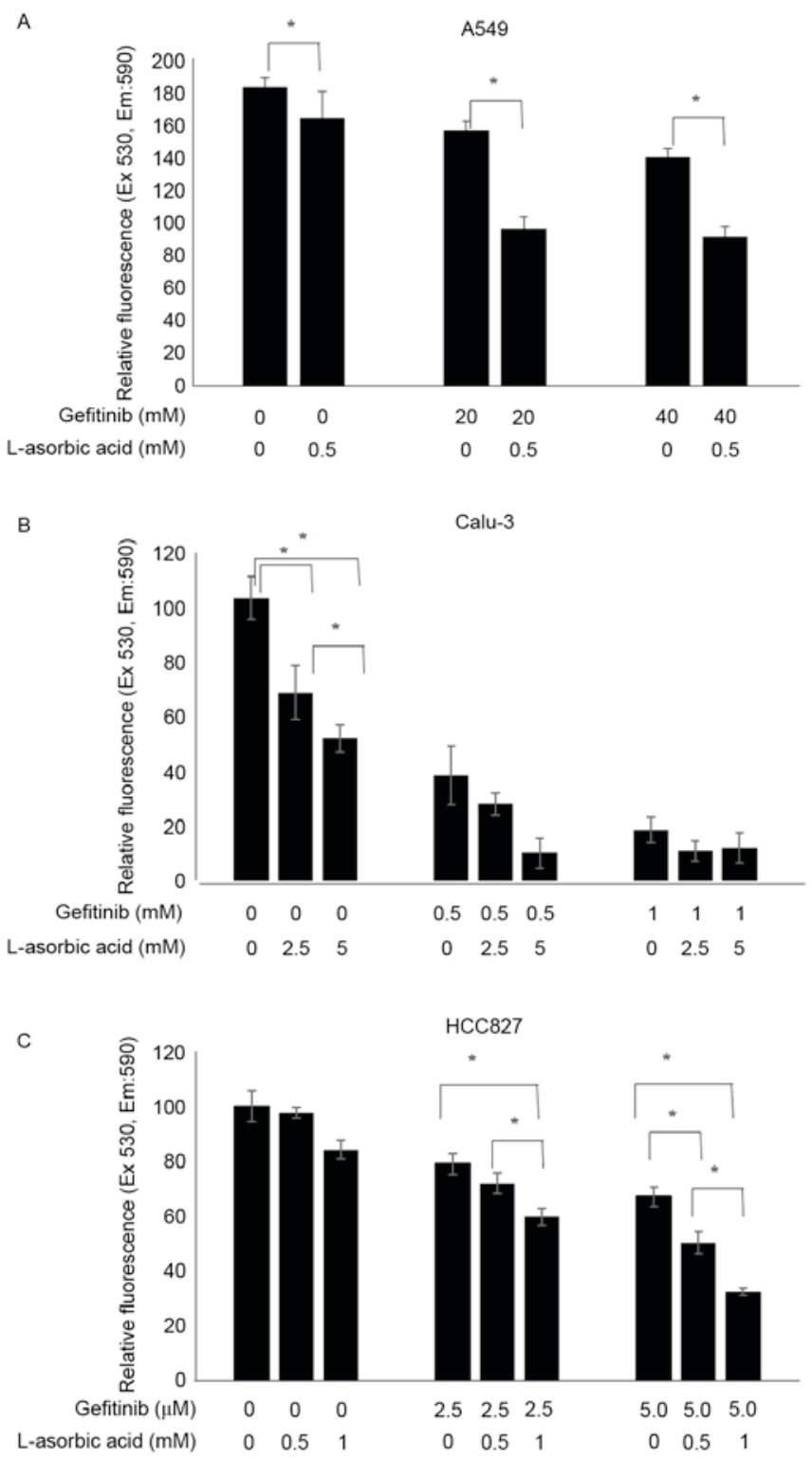

Figure 1. Increased antiproliferative activity of gefitinib with L-ascorbic acid in non-small cell lung cancer cell lines. A total of $1 \times 10^{6}$ cells were incubated with various concentrations of $\mathrm{L}$-ascorbic acid and/or gefitinib, and the cytotoxic effects were assessed using an AlamarBlue assay. Cells were pretreated with L-ascorbic acid for $1 \mathrm{~h}$, followed by gefitinib treatment for $48 \mathrm{~h}$. Cell viabilities are expressed as the ratio of the absorbance of treated cells to control cells. Independent experiments were performed in triplicate and the data are presented as the mean \pm standard deviation. (A) A549 cells exposed to 0,20 and $40 \mu \mathrm{M}$ gefitinib and 0 and $0.5 \mathrm{mM} \mathrm{L}$-ascorbic acid. (B) Calu-3 cells exposed to $0,0.5$ and $1 \mu \mathrm{M}$ gefitinib and $0,2.5$ and $5 \mathrm{mM} \mathrm{L}$-ascorbic acid. (C) HCC827 cells exposed to 0,2.5 and 5.0 $\mathrm{nM}$ gefitinib and 0, 0.5 and $1 \mathrm{mM}$ L-ascorbic acid. "P $<0.05$, statistically significant difference between the groups. Ex, excitation; Em, emission.

growth inhibition (Fig. 2). Similar results were observed in all three cell lines examined.

Changes in the cell cycle and ROS production effected by gefitinib and L-ascorbic acid. The combination of L-ascorbic acid with gefitinib demonstrated a synergistic reduction in the number of cells in the $\mathrm{S}$ phase. In the Calu-3 cells, the percentage of cells in $\mathrm{S}$ phase of the cell cycle was reduced from $35.8 \%$ in the control cells to $17.9 \%$ in cells treated with gefitinib alone; this percentage was $23.1 \%$ in cells treated

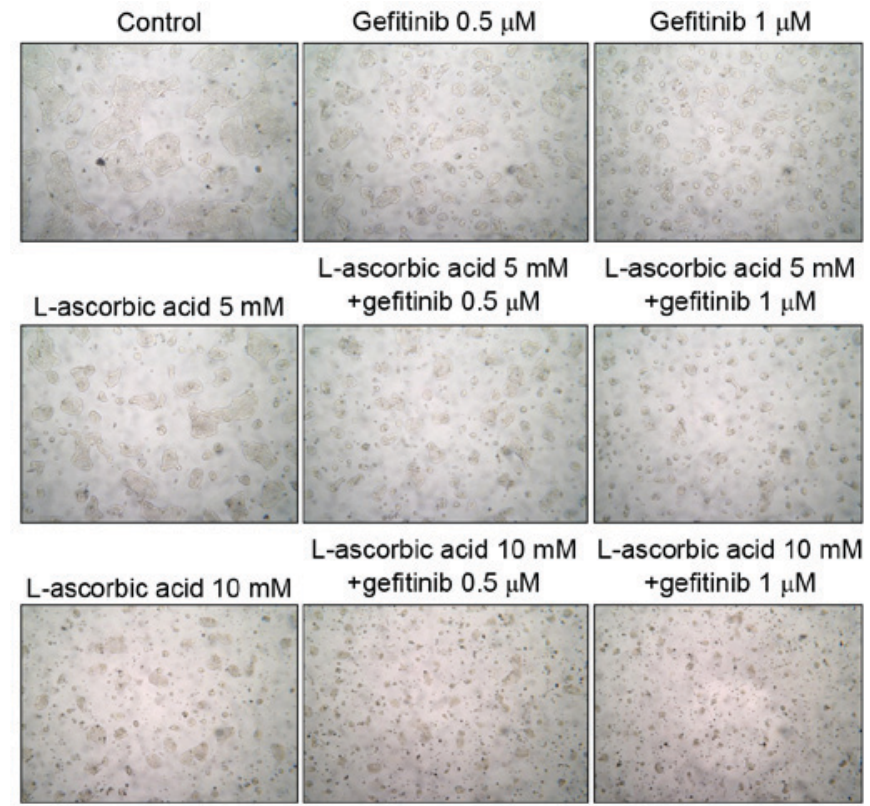

Figure 2. Microscopic images of Calu-3 cells treated with gefitinib and/or L-ascorbic acid. (Microscopic images were captured at magnification, x100, to illustrate the relative cellular growth patterns. A total of $1 \times 10^{6}$ cells were cultured in T25 culture flasks with/without L-ascorbic acid and gefitinib at various concentrations: 0.5 or $1 \mu \mathrm{M}$ of gefitinib and 5 or $10 \mathrm{mM} \mathrm{L}$-ascorbic acid. Cells were pre-treated with L-ascorbic acid for $1 \mathrm{~h}$ and then treated with gefitinib for $48 \mathrm{~h}$. The figure is representative of three independent experiments.

with L-ascorbic acid alone and $11 \%$ in cells co-treated with gefitinib and L-ascorbic acid. The highest observed arrest in the $\mathrm{G}_{2}$ phase was with L-ascorbic acid alone, and gefitinib did not induce $G_{2}$ arrest. The effect of $L$-ascorbic acid on $G_{2}$ arrest was neutralized when it was administered in combination with gefitinib. Also, the antioxidant activity of L-ascorbic acid was observed: In Calu-3 cells, blocking EGFR tyrosine kinase with gefitinib induced high intracellular levels of ROS. This action was attenuated by the antioxidant L-ascorbic acid, which reduced intracellular ROS levels in Calu-3 cells to approximately the level observed in the untreated cells (Fig. 3).

Changes in EGFR phosphorylation following treatment with gefitinib and L-ascorbic acid. A total of three antibodies, Tyr992, Tyr1068 and Tyr845, were used to identify different phosphorylation loci of the EGFR. The addition of L-ascorbic acid to gefitinib did not significantly modify the phosphorylation levels of Erk1/2, Stat3 or EGFR in A549 cells, but slightly reduced the phosphorylation levels of Akt (Fig. 4, left panel). In Calu-3 cells, treatment with L-ascorbic acid alone was not observed to have a significant effect on EGFR phosphorylation or the associated downstream signaling pathways. By contrast, L-ascorbic acid co-administered with gefitinib decreased the phosphorylation levels of Akt and Erk1/2. The phosphorylation level of Stat 3 was not significantly altered following the co-administration of L-ascorbic acid with gefitinib (Fig. 4, middle panel). In HCC827 cells, which exhibit an EGFR mutation and are sensitive to gefitinib, L-ascorbic acid administered in combination with gefitinib was not observed to significantly affect the signaling cascades downstream of the EGFR pathway. Monotherapy with gefitinib decreased 
A

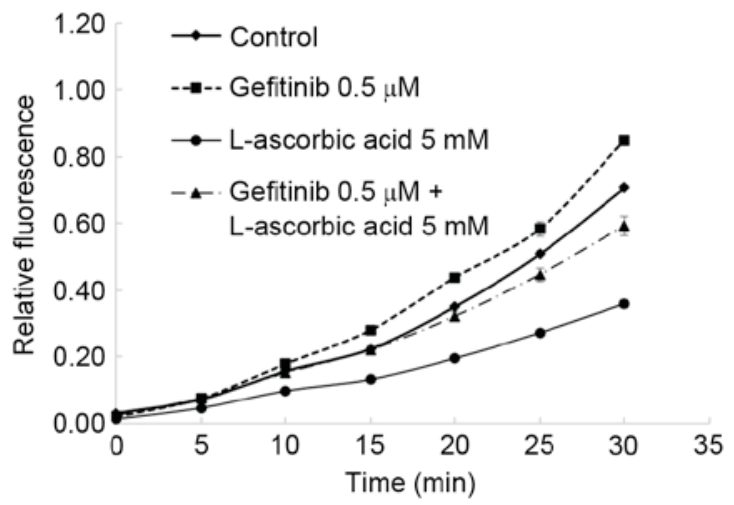

$B$

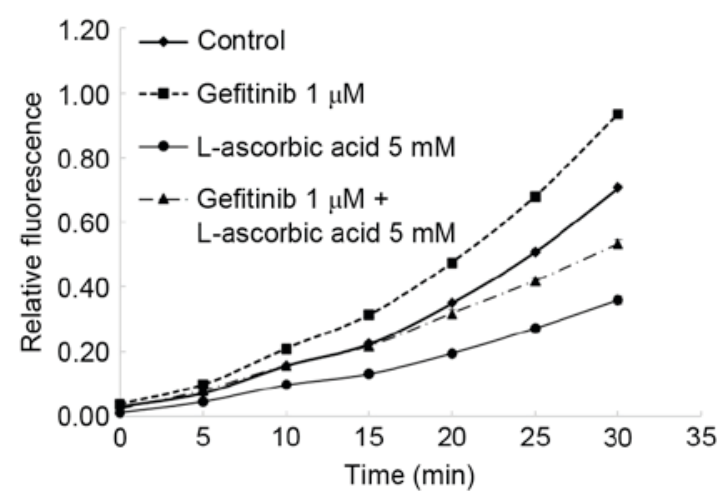

Figure 3. Changes in ROS in Calu-3 cells with L-ascorbic acid and/or gefitinib. A total of 1x10 ${ }^{4}$ cells in 96-well plates were treated with $5 \mathrm{mM}$ L-ascorbic acid and/or 0.5-1 $\mu \mathrm{M}$ gefitinib. (A and B) Using the DCFH-DA method (50 $\mu \mathrm{M}$ DCFH-DA) to detect ROS, L-ascorbic acid reduced intracellular ROS levels in Calu-3 cells to approximately control cell levels. Relative fluorescence was measured for $30 \mathrm{~min}$. The figure is representative of three independent experiments. ROS, reactive oxygen species; DCFH-DA, 2',7'-dichlorodihydrofluorescein diacetate.

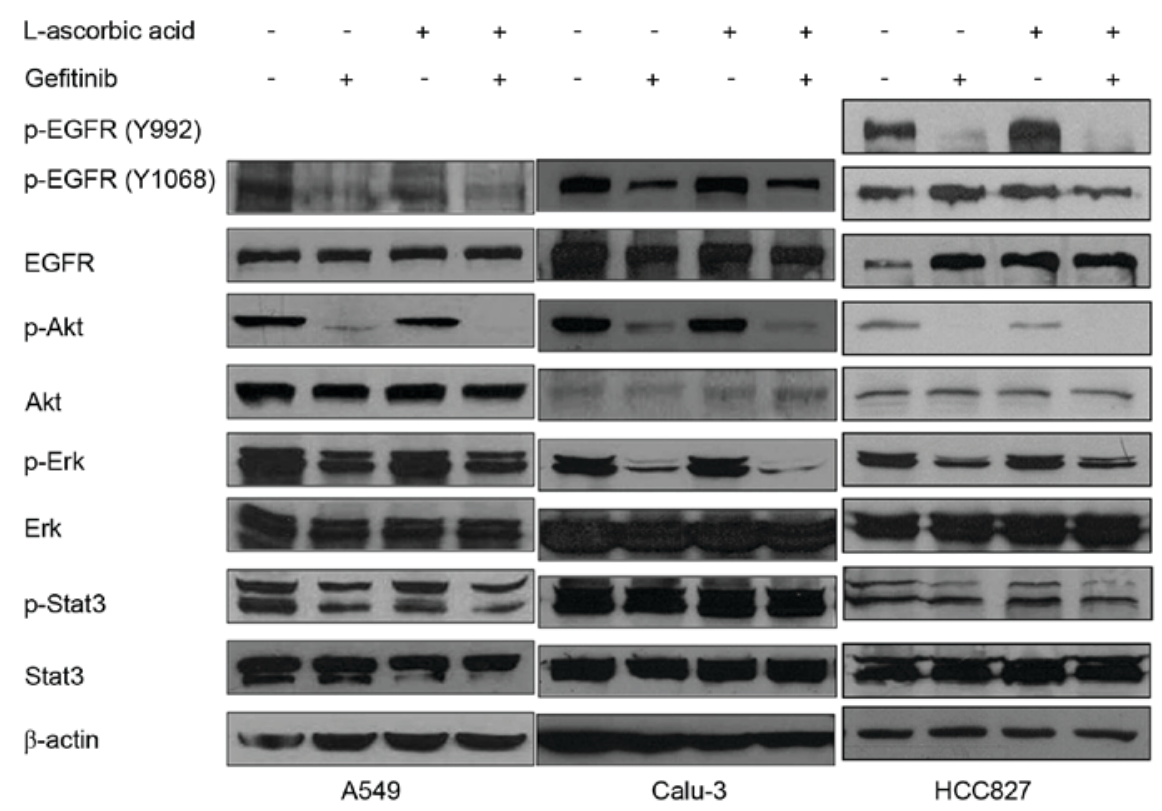

Figure 4. Immunoblotting analysis of gefitinib and/or L-ascorbic acid therapy in cancer cell lines. A total of $2 \times 10^{6}$ cells were cultured in serum-free medium with L-ascorbic acid or gefitinib. Calu-3 cells were pretreated with L-ascorbic acid for 30 min prior to gefitinib treatment, which was maintained for $2 \mathrm{~h}$. A total of three antibodies were used to detect the various phosphorylation sites of EGFR. A549 cells were treated with $0.5 \mathrm{mM}$ L-ascorbic acid and $20 \mu \mathrm{M}$ gefitinib; Calu-3 cells were treated with $2.5 \mathrm{mM} \mathrm{L}$-ascorbic acid and $0.5 \mu \mathrm{M}$ gefitinib; HCC 827 cells were treated with $1 \mathrm{mM} \mathrm{L}$-ascorbic acid and $0.005 \mu \mathrm{M}$ gefitinib. The figure is representative of three independent experiments. EGF, epidermal growth factor; EGFR, EGF receptor; p, phosphorylated; Akt, protein kinase B; Erk, extracellular signal-regulated kinases; Stat3, signal transducer and activator of transcription 3.

the phosphorylation levels of the downstream molecules of the EGFR pathway, including Akt, in the HCC827 cell line (Fig. 4, right panel), but no significance was observed. It was also examined whether changes in ROS affected the signaling cascades downstream of the EGFR signaling pathway.

\section{Discussion}

Numerous small molecules have been developed to replace cytotoxic chemotherapy agents in cancer therapeutics; however, the development of novel resistance to these drugs, along with resistance mechanisms, remains problematic. Mutations in the receptor kinase domains of cancer cells are the principal cause of resistance to tyrosine kinase inhibitor therapy $(12,17,29)$. Imatinib mesylate, which is applied clinically in the treatment of chronic myelogenous leukemia (CML), is the first small-molecule drug for which resistance to tyrosine kinase inhibitors was recognized; the mechanism for resistance was identified to originate from a mutation in the kinase domain $(7,13,31)$. The increase in intracellular ROS production induced by imatinib mesylate in patients with CML causes genetic instability and gene mutations, leading to mutation of the kinase domain and subsequent drug resistance. Antioxidants may decrease the levels of ROS present in cells and, therefore, decrease the risk of gene mutations and associated drug resistance (32).

Various previous in vitro and in vivo studies have suggested that certain antioxidants may increase the effects 
of cytotoxic therapy. However, clinical studies using antioxidants as an adjuvant to chemotherapy have so far been unsuccessful $(10,19,25,28,33,34)$. L-ascorbic acid may function as either a pro-oxidant or an antioxidant at physiological micromolar concentrations (normal range, $<0.1 \mathrm{mM}$ ) in the presence of trace amounts of transition metals including copper and iron (20,34-40). There is controversy regarding the potential role and dose of L-ascorbic acid that should be recommended for use in cancer therapy (40). Gefitinib is the first small-molecule drug developed to inhibit tyrosine kinase in human NSCLC (41). Mutant forms of EGFR and increased EGFR copy numbers are considered to be successful predictive biomarkers for therapeutic responses.

Similar to imatinib mesylate, ROS may induce changes in cell signaling, genetic instability and other various steps in intracellular pathways. One of the functions of intracellular ROS is to decrease phosphatase activity and to upregulate tyrosine kinase once at a certain concentration; thus, ROS may serve a role in carcinogenesis (31). At present, there have been few studies on the effects of ROS on the phosphorylation of EGFR (42).

The present study hypothesized that ROS affects EGFR kinase activity and the sensitivity of cancer cells to EGFR tyrosine kinase inhibitor therapy, and that L-ascorbic acid may have an additive or synergistic effect when co-administered with an EGFR tyrosine kinase inhibitor. As the EGFR mutation is an important biomarker for the response to gefitinib, three human NSCLC cell lines were used, including Calu-3 and A549 (wild-type EGFR) and HCC827, which has a mutation in the EGFR tyrosine kinase domain (E746-A750 deletion) and is known to respond to gefitinib. The effects of L-ascorbic acid and gefitinib were synergistic in all cell lines when administered at various dosages. In the present study, gefitinib acted as a pro-oxidant and L-ascorbic acid attenuated the elevation in ROS levels in lung cancer cell lines. It was also revealed that $\mathrm{L}$-ascorbic acid monotherapy reduced the percentage of Calu- 3 cells in the $\mathrm{S}$ phase, and that this effect was augmented when administered in combination with gefitinib. Thomas et al demonstrated that L-ascorbic acid induces transient cell cycle arrest by delaying the accumulation and activation of $C d c 25 C$ (42).

The antiproliferative and anticancer mechanisms of L-ascorbic acid and gefitinib differ. L-ascorbic acid may kill or inhibit the growth of numerous tumor cell lines and also increase the potency of certain radiosensitizing drugs (43). Beyond its antioxidant role, the exact mechanisms underlying the effects L-ascorbic acid have yet to be elucidated. Although different concentrations of L-ascorbic acid were chosen for each cell line, none of the selected concentrations killed all the cells. In the present study, L-ascorbic acid administered alone inhibited cancer cell growth through its antioxidant function and by downregulating EGFR phosphorylation. Gefitinib alone generated ROS, inhibited kinase activity and downregulated Akt and Erk expression. In order to identify the optimal redox environment for EGFR tyrosine kinase inhibitors to obtain a maximum anticancer effect, the effect of ROS in EGFR tyrosine kinase inhibitor therapy was examined using nonspecific ROS blocking agents. It is not likely that ROS were the leading cause of the antitumor effects in the present study. These results indicate that $\mathrm{L}$-ascorbic acid acts via its own antitumor mechanisms that are separate to ROS activity, and that it is involved in the inhibition of the EGFR signaling cascade.

In conclusion, the present study has demonstrated that, when co-administered with gefitinib, L-ascorbic acid functions as an antioxidant and is associated with the downregulation of EGFR phosphorylation in three NSCLC cell lines. However, several issues remain to be resolved, including the practical delivery of a clinically relevant therapeutic dose of L-ascorbic acid, the optimal redox status that exhibits an antitumor effect and the in vivo responses. It is suggested that L-ascorbic acid may overcome the wild-type EGFR tyrosine kinase inhibitor resistance and induce a synergistic response when co-administered with EGFR tyrosine kinase inhibitors in NSCLC. These results also suggest that improved clinical outcomes in lung cancer therapy may be obtained through L-ascorbic acid therapy combined with an EGFR tyrosine kinase inhibitor therapy such as gefitinib or erlotinib.

\section{Acknowledgements}

The present study was supported partly by Basic Science Research Program through the National Research Foundation of Korea (NRF) funded by the Ministry of Education (grant. no. 2013R1A2A2A01067836) and partly by intramural Research Promotion Grants from Ewha Womans University, School of Medicine.

\section{References}

1. Ferlay J, Soerjomataram I, Ervik M, Dikshit R, Eser S, Mathers C, Rebelo M, Parkin DM, Forman D and Bray F: GLOBOCAN 2012 v1.0, Cancer Incidence, Mortality and Prevalence Worldwide in 2012. IARC CancerBase No. 11 (Internet). International Agency for Research on Cancer, Lyon, France, 2013. http://globocan.iarc.fr.

2. Siegel R, Naishadham D and Jemal A: Cancer statistics, 2013. CA Cancer J Clin 63: 11-30, 2013.

3. Vincent TD, Steven AR and Theodore SL: DeVita, Hellman and Rosenberg's Cancer: Principles \& Practice of Oncology. 9th edition. Wolters Kluwer Health/Lippincott Williams \& Wilkins, Philadelphia, PA, pp799-845, 2011.

4. Lam KC and Mok TS: Targeted therapy: An evolving world of lung cancer. Respirology 16: 13-21, 2011.

5. Braughler JM, Duncan LA and Chase RL: The involvement of iron in lipid peroxidation. Importance of ferric to ferrous ratios in initiation. J Biol Chem 261: 10282-10289, 1986.

6. Cappuzzo F, Varella-Garcia M, Shigematsu H, Domenichini I, Bartolini S, Ceresoli GL, Rossi E, Ludovini V, Gregorc V, Toschi L, et al: Increased HER2 gene copy number is associated with response to gefitinib therapy in epidermal growth factor receptor-positive non-small-cell lung cancer patients. J Clin Oncol 23: 5007-5018, 2005

7. Carter TA, Wodicka LM, Shah NP, Velasco AM, Fabian MA, Treiber DK, Milanov ZV, Atteridge CE, Biggs WH III, Edeen PT, et al: Inhibition of drug-resistant mutants of ABL, KIT, and EGF receptor kinases. Proc Natl Acad Sci USA 102: 11011-11016, 2005.

8. D'Incecco A and Cappuzzo F: Gefitinib for non-small-cell lung cancer treatment. Expert Opin Drug Saf 10: 987-996, 2011.

9. Wang F, Wang LD, Li B and Sheng ZX: Gefitinib compared with systemic chemotherapy as first-line treatment for chemotherapy-naive patients with advanced non-small cell lung cancer: A meta-analysis of randomised controlled trials. Clin Oncol (R Coll Radiol) 24: 396-401, 2012.

10. Duarte TL and Lunec J: Review: When is an antioxidant not an antioxidant? A review of novel actions and reactions of vitamin C. Free Radic Res 39: 671-686, 2005.

11. Giordano CR, Mueller KL, Terlecky LJ, Krentz KA, Bollig-Fischer A, Terlecky SR and Boerner JL: A targeted enzyme approach to sensitization of tyrosine kinase inhibitor-resistant breast cancer cells. Exp Cell Res 318: 2014-2021, 2012. 
12. Kobayashi S, Boggon TJ, Dayaram T, Jänne PA, Kocher O, Meyerson M, Johnson BE, Eck MJ, Tenen DG and Halmos B: EGFR mutation and resistance of non-small-cell lung cancer to gefitinib. N Engl J Med 352: 786-792, 2005.

13. Koptyra M, Falinski R, Nowicki MO, Stoklosa T, Majsterek I, Nieborowska-Skorska M, Blasiak J and Skorski T: BCR/ABL kinase induces self-mutagenesis via reactive oxygen species to encode imatinib resistance. Blood 108: 319-327, 2006.

14. Lynch TJ, Bell DW, Sordella R, Gurubhagavatula S, Okimoto RA, Brannigan BW, Harris PL, Haserlat SM, Supko JG, Haluska FG, et al: Activating mutations in the epidermal growth factor receptor underlying responsiveness of non-small-cell lung cancer to gefitinib. N Engl J Med 350: 2129-2139, 2004.

15. Tartarone A and Lerose R: Clinical approaches to treat patients with non-small cell lung cancer and epidermal growth factor receptor tyrosine kinase inhibitor acquired resistance. Ther Ady Respir Dis 9: 242-250, 2015.

16. Russo A, Franchina T, Ricciardi GR, Picone A, Ferraro G, Zanghì M, Toscano G, Giordano $\mathrm{A}$ and Adamo $\mathrm{V}$ : A decade of EGFR inhibition in EGFR-mutated non small cell lung cancer (NSCLC): Old successes and future perspectives. Oncotarget 6 : 26814-26825, 2015.

17. Huang $\mathrm{L}$ and Fu L: Mechanisms of resistance to EGFR tyrosine kinase inhibitors. Acta Pharm Sin B 5: 390-401, 2015.

18. Tan CS, Gilligan D and Pacey S: Treatment approaches for EGFR-inhibitor-resistant patients with non-small-cell lung cancer. Lancet Oncol 16: e447-e459, 2015.

19. Meves A, Stock SN, Beyerle A, Pittelkow MR and Peus D $\mathrm{H}(2) \mathrm{O}(2)$ mediates oxidative stress-induced epidermal growth factor receptor phosphorylation. Toxicol Lett 122: 205-214, 2001

20. Miller DM, Buettner GR and Aust SD: Transition metals as catalysts of 'autoxidation' reactions. Free Radic Biol Med 8: 95-108, 1990.

21. Monteiro HP, Ivaschenko Y, Fischer R and Stern A: Ascorbic acid inhibits protein tyrosine phosphatases in NIH 3T3 cells expressing human epidermal growth factor receptors. Int J Biochem 25: 1859-1864, 1993.

22. Nicholson RI, Gee JM and Harper ME: EGFR and cancer prognosis. Eur J Cancer 37 (Suppl 4): S9-S15, 2001.

23. Ono M, Hirata A, Kometani T, Miyagawa M,Ueda S, Kinoshita H, Fujii T and Kuwano M: Sensitivity to gefitinib (Iressa,ZD1839) in non-small cell lung cancer cell lines correlates with dependence on the epidermal growth factor (EGF) receptor/extracellular signal-regulated kinase $1 / 2$ and EGF receptor/Akt pathway for proliferation. Mol Cancer Ther 3: 465-472, 2004.

24. Paez JG, Jänne PA, Lee JC, Tracy S, Greulich H, Gabriel S Herman P, Kaye FJ, Lindeman N, Boggon TJ, et al: EGFR mutations in lung cancer: Correlation with clinical response to gefitinib therapy. Science 304: 1497-1500, 2004

25. Wenzel U, Nickel A, Kuntz S and Daniel H: Ascorbic acid suppresses drug-induced apoptosis in human colon cancer cells by scavenging mitochondrial superoxide anions. Carcinogenesis 25 : 703-712, 2004

26. Pal SK and Pegram M: Epidermal growth factor receptor and signal transduction: Potential targets for anti-cancer therapy. Anticancer Drugs 16: 483-494, 2005.

27. Petrelli F, Borgonovo K, Cabiddu M and Barni S: Efficacy of EGFR tyrosine kinase inhibitors in patients with EGFR-mutated non-small-cell lung cancer: A meta-analysis of 13 randomized trials. Clin Lung Cancer 13: 107-114, 2012.

28. Prasad KN and Kumar R: Effect of individual and multiple antioxidant vitamins on growth and morphology of human nontumorigenic and tumorigenic parotid acinar cells in culture. Nutr Cancer 26: 11-19, 1996.
29. Lin Y, Wang X and Jin H: EGFR-TKI resistance in NSCLC patients: Mechanisms and strategies. Am J Cancer Res 4: 411-435, 2014.

30. Collins L and Franzblau SG: Microplate alamar blue assay versus BACTEC 460 system for high-throughput screening of compounds against Mycobacterium tuberculosis and Mycobacterium avium. Antimicrob Agents Chemother 41: 1004-1009, 1997

31. Tarumoto T, Nagai T, Ohmine K, Miyoshi T, Nakamura M, Kondo T, Mitsugi K, Nakano S, Muroi K, Komatsu N and Ozawa K: Ascorbic acid restores sensitivity to imatinib via suppression of Nrf2-dependent gene expression in the imatinib-resistant cell line. Exp Hematol 32: 375-381, 2004.

32. Prasad KN, Sinha PK, Ramanujam M and Sakamoto A: Sodium ascorbate potentiates the growth inhibitory effect of certain agents on neuroblastoma cells in culture. Proc Natl Acad Sci USA 76: 829-832, 1979

33. Pathak AK, Bhutani M, Guleria R, Bal S, Mohan A, Mohanti BK, Sharma A, Pathak R, Bhardwaj NK, Prasad KN and Kochupillai V: Chemotherapy alone vs. chemotherapy plus high dose multiple antioxidants in patients with advanced non small cell lung cancer. J Am Coll Nutr 24: 16-21, 2005.

34. Sane AT, Cantin AM, Paquette B and Wagner JR: Ascorbate modulation of $\mathrm{H}(2) \mathrm{O}(2)$ and camptothecin-induced cell death in Jurkat cells. Cancer Chemother Pharmacol 54: 315-321, 2004.

35. Rhee SG: Cell signaling. $\mathrm{H} 2 \mathrm{O} 2$, a necessary evil for cell signaling. Science 312: 1882-1883, 2006.

36. Rosell R, Ichinose Y, Taron M, Sarries C, Queralt C, Mendez P, Sanchez JM, Nishiyama K, Moran T, Cirauqui B, et al: Mutations in the tyrosine kinase domain of the EGFR gene associated with gefitinib response in non-small-cell lung cancer. Lung Cancer 50: 25-33, 2005.

37. Sasazuki S, Hayashi T, Nakachi K, Sasaki S, Tsubono Y, Okubo S, Hayashi M and Tsugane S: Protective effect of vitamin $\mathrm{C}$ on oxidative stress: A randomized controlled trial. Int J Vitam Nutr Res 78: 121-128, 2008.

38. Chakraborthy A, Ramani P, Sherlin HJ, Premkumar P and Natesan A: Antioxidant and pro-oxidant activity of Vitamin C in oral environment. Indian J Dent Res 25: 499-504, 2014.

39. Buettner GR and Jurkiewicz BA: Catalytic metals, ascorbate and free radicals: Combinations to avoid. Radiat Res 145: 532-541, 1996.

40. Cieslak JA and Cullen JJ: Treatment of pancreatic cancer with pharmacological ascorbate. Curr Pharm Biotechnol 16: 759-770, 2015.

41. Miller VA, Kris MG, Shah N, Patel J, Azzoli C, Gomez J, Krug LM, Pao W, Rizvi N, Pizzo B, et al: Bronchioloalveolar pathologic subtype and smoking history predict sensitivity to gefitinib in advanced non-small-cell lung cancer. J Clin Oncol 22: 1103-1109, 2004

42. Thomas CG, Vezyraki PE, Kalfakakou VP and Evangelou AM: Vitamin $C$ transiently arrests cancer cell cycle progression in $\mathrm{S}$ phase and $\mathrm{G} 2 / \mathrm{M}$ boundary by modulating the kinetics of activation and the subcellular localization of Cdc25C phosphatase. J Cell Physiol 205: 310-318, 2005.

43. Leekha A, Gurjar BS, Tyagi A, Rizvi MA and Verma AK: Vitamin $C$ in synergism with cisplatin induces cell death in cervical cancer cells through altered redox cycling and p53 upregulation. J Cancer Res Clin Oncol 142: 2503-2514, 2016. 